\title{
Biology of Angiogenesis and Invasion in Glioma
}

\author{
Matthew C. Tate and Manish K. Aghi \\ Department of Neurological Surgery, University of California, San Francisco, California 94143
}

Summary: Treatment of adult brain tumors, in particular glioblastoma, remains a significant clinical challenge, despite modest advances in surgical technique, radiation, and chemotherapeutics. The formation of abnormal, dysfunctional tumor vasculature and glioma cell invasion along white matter tracts are believed to be major components of the inability to treat these tumors effectively. Recent insight into the fundamental processes governing glioma angiogenesis and invasion provide a renewed hope for development of novel strategies aimed at reducing the morbidity of this uniformly fatal disease. In this review, we discuss back- ground biology of the blood brain barrier and its pertinence to blood vessel formation and tumor invasion. We will then focus our attention on the biology of glioma angiogenesis and invasion, and the key mediators of these processes. Last, we will briefly discuss recent and ongoing clinical trials targeting mediators of angiogenesis or invasion in glioma patients. The findings provide a renewed hope for those endeavoring to improve treatment of patients with glioma by providing a novel set of rational targets for translational drug discovery. Key Words: Angiogenesis, glioblastoma, VEGF, invasion, extracellular matrix.

\section{INTRODUCTION}

Glioblastoma remains a uniformly fatal disease, despite advances in surgical and medical therapy. Two major aspects of glioma biology that contributes to this recalcitrance are the formation of new blood vessels through the process of angiogenesis and the invasion of glioma cells through white matter tracts, which are hallmarks of glioblastoma. Due to angiogenesis, the glioma vessel structure is markedly abnormal, resulting in decreased delivery of chemotherapies, increasing tumor hypoxia, and producing edema with its clinical consequences. These abnormal blood vessels in gliomas have also been shown to create a vascular niche that houses glioma stem cells, ${ }^{1}$ cells making up a small fraction of the glioma that have been shown to be capable of giving rise to the entire tumor ${ }^{2}$ and which are believed to represent a source of treatment resistance, suggesting that targeting the abnormal glioma vasculature could enable targeting of this glioma stem cell population. Recent insights into the fundamental processes and molecular changes accompanying glioma invasion and angiogene-

Address correspondence and reprint requests to: Manish K. Aghi, Department of Neurological Surgery, University of California, 505 Parnassus Avenue, Room M779, San Francisco, CA 94143-0112. E-mail: aghim@neurosurg.ucsf.edu. sis are providing exciting new therapeutic targets to deal with this uniformly fatal disease.

In this review, we first discuss the normal structure and physiology of the blood brain barrier (BBB), its alterations in glioma patients, and the physiologic effects of its alteration during tumor angiogenesis. We then review the fundamental processes involved in formation of new blood vessels during glioma growth, focusing on alterations of both pro-angiogenic and anti-angiogenic signaling pathways. We then discuss the biology enabling gliomas to invade along white matter tracts. We conclude by discussing how these advances in our understanding of glioma angiogenesis and invasion have provided us with a new set of targets that have been studied in recent and ongoing clinical trials. These studies in the laboratory and in the clinic will likely translate into improvements in the morbidity and mortality of patients afflicted with this devastating disease.

\section{THE BLOOD BRAIN BARRIER IN GLIOMA}

In the normal adult brain, the blood brain barrier (BBB) is established by the coordination of three primary cell types (endothelial cells, pericytes, and astrocytes), which function as a selective corridor for the flow of molecules between the systemic circulation and cerebral tissues. ${ }^{3}$ Although flow of hydrophilic molecules between endothelial cells is limited in a size-dependent 
manner by tight junctions, transport of molecules across endothelial cells is more complex and involves active transport mechanisms. Of relevance to brain tumor biology, P-glycoprotein/drug-resistance proteins function to actively export "foreign" molecules from the brain into the systemic circulation, one of the known mechanisms of chemotherapeutic resistance in gliomas.

It has been well established that blood vessel structure and function become markedly abnormal in brain tumors. ${ }^{4}$ Cardinal features include hypoxic conditions as the tumor mass metabolic requirements outreach the vascular supply, resulting in an "angiogenic switch" that is marked by endothelial cell proliferation, necrosis, breakdown of existing blood vessels and extracellular matrix (ECM), and eventually new vessel formation. ${ }^{5,6}$ Glioblastomas, one of the most well-studied tumor types with regard to angiogenesis, are known to have blood vessels of increased diameter, high permeability, thickened basement membranes, and highly proliferative endothelial cells, the latter being part of the World Health Organization histologic definition of glioblastoma. ${ }^{7}$ It has been established that permeability of glioma vessels is enhanced with respect to those in normal brain tissue, although the degree to which this is true is complex and varies with respect to time and location. ${ }^{3}$ Interestingly, even though brain tumor vessels appear more "leaky" than their normal tissue counterpart, at least some elements of the BBB in glioblastomas remain intact, as is evidenced by increased transvascular transport seen in subcutaneous brain tumor transplants relative to the same tumor implanted intracerebrally. ${ }^{8}$ Permeability is varied, even within a single tumor in the brain, and this heterogeneity of permeability contributes to uneven distribution of transport products, such as oxygen and chemotherapeutics within the tumor bed.
Vascular endothelial growth factor (VEGF) is one of the best characterized permeability factors expressed in gliomas and has been shown to directly contribute to BBB breakdown in gliomas. ${ }^{3}$ VEGF expression is tightly coupled to conditions of hypoxia and acidosis, two features of the glioma microenvironment. Increased permeability of tumor blood vessels induced by factors such as VEGF results in elevated interstitial pressure and significant intracerebral edema, a hallmark of human glioma. In addition, elevated interstitial pressure decreases the net transport of medication to tumor cells ${ }^{9}$ and increases access of tumor cells to the vasculature, which is one possible mechanism for the wide dissemination seen in glioblastoma. ${ }^{10}$ Thus strategies that serve to decrease permeability of tumor blood vessels or halt angiogenesis hold the promise of decreasing brain edema and enhancing chemotherapy delivery.

\section{FUNDAMENTAL PROCESSES OF NEW BLOOD VESSEL FORMATION}

\section{Modes of blood vessel formation in glioma}

Formation of new blood vessels occurs by one of three methods: 1) angiogenesis, 2) vasculogenesis, or 3) arteriogenesis (FIG. 1). ${ }^{11,12}$ Angiogenesis is the formation of new blood vessels by rerouting or remodeling existing ones, and is believed to be the primary method of vessel formation in gliomas, which serves as the focus of this article. Vasculogenesis was classically considered an embryonic process, but has since been identified in tumors, involves the de novo production of blood vessels from circulating marrow-derived endothelial progenitor cells that are recruited to the tumor, and appears to be at least in part regulated by tumor-secreted stromal-derived factor 1 under the control of the hypoxia-induced tran-

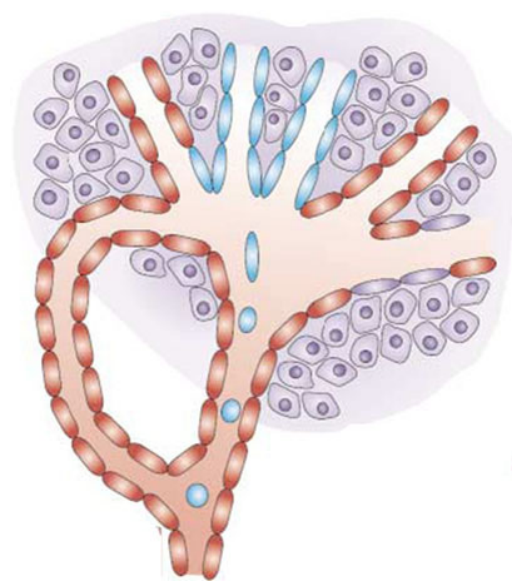

\section{(6) Tumor cells}

\section{Marrow-derived endothelial progenitor cell (EPC)}

Endothelium from vasculogenesis (derived from circulating marrow-derived EPCs)

\section{Endothelium from angiogenesis (derived from pre-existing vessels)}

FIG. 1. Mechanisms of tumor vessel formation. Recent evidence suggests that tumor cells generate the endothelial lining of blood vessels by angiogenesis (the re-routing of pre-existing blood vessels into the tumor) or vasculogenesis (the recruitment of circulating bone marrow-derived endothelial progenitor cells or endothelial progenitor cells toward the tumor where they differentiate into mature endothelium). The process of arteriogenesis is not believed to contribute to tumor vessel formation. Tumor pericytes, which surround and nourish the endothelium, also appear to originate through locally-derived or marrow-derived sources. Schematic modified from Rafii et al. ${ }^{135}$ 
scription factor hypoxia-inducible factor $1 \alpha$ (HIF $1 \alpha)$, and is reviewed elsewhere. ${ }^{13,14}$ Finally, arteriogenesis is a third process that refers to enlarged arteriolar networks produced to sustain increased oxygen demands, but does not appear to play a significant role in tumor biology. ${ }^{12}$

\section{Blood vessel breakdown: step 1 of angiogenesis}

The first step in forming new blood vessels from existing ones is the dissolution of aspects of native vessels. Angiopoietin-1 (Ang-1) and its receptor Tie-2 are key components of this process. In the normal brain, Ang-1 binds to Tie-2 resulting in a close association between pericytes and endothelial cells, resulting in stability of the vasculature. ${ }^{15,16}$ However, in the context of tissue hypoxia, such as that seen in glioblastoma multiforme (GBM), Ang-2 is upregulated in endothelial cells whereas Ang-1 is increased in tumor cells. ${ }^{17}$ It has been hypothesized that increased Ang-2 expression, which appears to be an antagonist of Tie-2, leads to the initial regression of blood vessels seen in early tumor-mediated angiogenesis. ${ }^{17,18}$ Eventually, matrix-metalloproteinase (MMP)-2 expression is increased through Tie-2 signaling, and in conjunction with VEGF promotes continuation of angiogenesis. ${ }^{19,20}$

\section{Breakdown of ECM and migration of cells to form new blood vessels: step 2 of angiogenesis}

Following regression of native vessels, degradation of the vessel basement membrane and surrounding ECM to allow for invasion of endothelial cells is an integral part of the ongoing angiogenic process. ${ }^{21}$ MMPs are one class of molecules that have been shown to play an integral role in this process. Specific to brain tumor angiogenesis, the collagenases MMP-2 and MMP-9 have been shown to play a major role, ${ }^{22,23}$ and their expression is associated with a poor prognosis in human glioma. ${ }^{24}$ Hypoxia is a strong inducer of MMP-2 and MMP-9 expression, and these two molecules appear to have a synergistic effect on basement membrane degradation as well as promoting pro-angiogenic signaling by exposing endothelial cells to molecules comprising the tumor ECM, including sequestered proteins such as VEGF and fibroblast growth factor (FGF). ${ }^{25}$ In addition to these pro-angiogenic effects, a number of molecules are expressed in the ECM that serve to inhibit proteolysis, including tumstatin, angiostatin, and arrestin. ${ }^{26}$

\section{Migration of endothelial cells and formation of new blood vessels: step 3 of angiogenesis}

After regression of existing vessels and breakdown of the basement membrane, endothelial cells proliferate and begin migrating toward tumor cells expressing pro-angiogenic compounds. Endothelial cell activation upregulates cell surface adhesion/migration molecules, such as integrins and CD44. ${ }^{12,27}$ Specifically, $\alpha_{\mathrm{v}} \beta_{3}$ and $\alpha_{5} \beta_{1}$ are upregulated in endothelial cells and stimulation during angiogenesis, which leads to increase cell adhesion, mi- gration, and survival. ${ }^{28-30}$ In addition to migration of endothelial cells, more evidence is emerging to suggest that pericyte migration, as part of the process of adult vasculogenesis, may an important part of tumor vessel formation in addition to the classic angiogenesis pathways. ${ }^{15}$ Platelet-derived growth factor (PDGF) secretion by activated endothelial cells recruits pericytes to the site of newly sprouting vessels to aid in establishment of a new basement membrane. ${ }^{31}$ Of the four PDGF family members (A to D), A and B are the two expressed by gliomas; whereas of the 2 PDGF tyrosine kinase receptors (i.e., PDGFR- $\alpha$ and PDGFR- $\beta$ ), PDGFR- $\alpha$ is expressed by glioma cells, suggesting a role in autocrine growth, whereas PDGFR- $\beta$ is expressed by glioma endothelium and pericytes, particularly the latter, suggesting its importance in the migration of pericytes into newly formed tumor blood vessels. The ability of a selective inhibitor of PDGFR- $\beta$ to block glioma growth and reduce vessel density suggests the importance of pericytes in glioma vessel stability. ${ }^{32}$ The complex final steps of tumor blood vessel formation are not well understood, but involve a dramatic change in the extracellular environment, including expression of high levels of embryonic ECM molecules, such as tenascin-C, as well as elevated VEGF and Ang-2 levels that likely contribute to the leakiness and disordered structure of these new vessels. ${ }^{12,33}$ The final product of glioma angiogenesis is a vasculature with highly tortuous dilated vessels, decreased density of astrocytic foot processes, alterations in endothelial cell adhesion molecule expression, disrupted basement membrane, and an increased ratio of small diameter vessels. ${ }^{10,34,35}$

\section{MOLECULAR BIOLOGY OF ANGIOGENESIS}

\section{Angiogenic switch - cellular and environmental sources}

Angiogenesis is activated in growing gliomas when the pro-angiogenic stimuli outweigh the anti-angiogenic stimuli (FIG. 2). These stimuli are secreted by both cellular (glioma cells, endothelial cells, and microglia) and environmental sources (the $\mathrm{ECM}^{36}$ or hypoxia ${ }^{37}$ influencing cellular secretion). The summation of these proand anti-angiogenic forces modulated by tissue hypoxia and genetic alterations establish the so-called "angiogenic switch" favoring glioma angiogenesis. The most potent activator of angiogenic mechanisms in brain tumors is tissue hypoxia. One well studied pathway is the HIF-1/VEGF-A pathway, which leads to endothelial cell proliferation and migration. ${ }^{38}$ However, additional HIF-1 independent pathways have been described, such as interleukin- 8 expression by microglia cells in response to hypoxia. ${ }^{39,40}$ In addition to activating pro-angiogenic pathways, hypoxic conditions also downregulate antiangiogenic pathways, thereby producing conditions fa- 


\section{ECM}

2. GLIOMA

TENASCIN-C
FIBRONECTIN
LAMININ-8

TUMOR CELLS

VEGF

bFGF

MICROGLIA

IL-8

ENDOTHELIUM NEUROPILINS

PRO-ANGIOGENIC

\section{ECM SPARCI
OSTEONECTIN}

ANTI-ANGIOGENIC
2. GLIOMA

TUMOR CELLS ENDOSTATIN

BAI1

ENDOTHELIUM

ANGIOSTATIN

TSP1, TSP2
FIG. 2. "The angiogenic switch" - balance of anti-angiogenic and pro-angiogenic stimuli in glioma. Once the balance tips towards pro-angiogenic, the tumor begins neovascularization. Sources of pro-angiogenic stimuli are glioma cells, endothelium, and microglia. Sources of anti-angiogenic stimuli are glioma cells and endothelium. BAI = brain angiogenesis inhibitor; bFGF = basic fibroblast growth factor; ECM = extracellular matrix; IL = interleukin; TSP $=$ thrombospondin.

voring growth of tumor blood vessels. ${ }^{12}$ Further, genetic instability, a hallmark of gliomas promotes angiogenesis independent of hypoxia, typically via chronic HIF activation via phosphoinositide 3-kinase (PI3K) or mitogenactivated protein kinase (MAPK) pathways. ${ }^{41,42}$ Below we discuss factors known to play a role in this restructuring of the vascular network.

\section{Pro-angiogenic factors}

Perhaps the most rigorously studied molecule with respect to angiogenesis of tumors is VEGF. Specifically, VEGF-A is known to be upregulated in glioblastoma and is produced by multiple cell types, including tumor cells, stromal, and inflammatory cells, ${ }^{43}$ and it regulates endothelial cell survival, proliferation, permeability, and migration primarily via the VEGF-receptor 2 (VEGFR2). ${ }^{44-48}$ VEGF-A is primarily induced by tissue hypoxia via the HIF- $1 \alpha$ pathway. Briefly, hypoxic conditions lead to dissociation of von Hippel Landau protein from HIF $1 \alpha$, decreasing its proteosomal-mediated degradation and allowing binding to the promoter region of several pro-angiogenic factors, such as a VEGF and stro- mal cell-derived factor-1 (SDF-1), which in turn activate angiogenic, vasculogenic, and survival pathways. ${ }^{38}$

In addition to direct actions on tumor endothelial cells where receptors VEGF-R1 and VEGF-R2 are upregulated relative to normal brain. VEGF can also be sequestered in the tumoral ECM. ${ }^{49}$ Interestingly, VEGF-R3, previously believed to be confined to lymphatic vessel endothelial cells (and thus not expressed in the normal brain) is expressed in endothelial cells of glioblastoma. ${ }^{50}$ VEGF-C and VEGF-D, ligands for VEGF-R3, are expressed in cells in close proximity to tumor endothelial cells, suggesting that a signaling pathway may exist in the glioma neovascular niche. ${ }^{10,50}$ Also, multiple growth factors implicated in angiogenesis, such as bFGF, epidermal growth factor (EGF), and PDGF have been shown to increase VEGF expression. ${ }^{38}$ The end result of VEGF signaling in tumors is production of immature, highly permeable blood vessels with subsequent poor maintenance of the BBB and parenchymal edema.,51

Based in part on the extensive research demonstrating its role in glioma angiogenesis, most of the clinical trials targeting angiogenesis in gliomas have targeted the VEGF pathway. The most notable of these trials were the phase II clinical trials of VEGF neutralizing antibody bevacizumab (avastin), in which a 23 -week median survival was found in recurrent glioma patients treated with bevacizumab combined with the chemotherapy agent irinotecan. ${ }^{52,53}$ These findings have led to an ongoing phase III clinical trial combining bevacizumab with temozolomide, the current standard of care for newly diagnosed glioma patients. The VEGF receptor has been targeted using pan-VEGF receptor tyrosine kinase inhibitor AZD2171 (cediranib), the subject of a phase II clinical trial in glioma, ${ }^{54}$ and the protein kinase $\mathrm{C}-\beta$ inhibitor enzastaurin, which is undergoing phase I/II clinical trails in glioma patients. ${ }^{55}$

In addition to VEGF, another well studied pro-angiogenic molecule in brain tumors is basic fibroblast growth factor. In glioma, FGF is expressed by tumor cells as well as in blood vessels. ${ }^{56}$ FGF-receptor 1 is upregulated in tumor cells and endothelial cells, while FGF-receptor 4 is expressed primarily in tumor cells. ${ }^{57,58}$ As has been observed in studies with VEGF, basic fibroblast growth factor can also be stored or trapped within the extracellular milieu of glioma. Animal studies involving function-blocking antibodies of FGF that demonstrate decreased tumor growth, suggesting a functional role for FGF in tumor propagation. ${ }^{59}$ In contrast to VEGF binding to its receptor on endothelial cells and stimulation of the PI3K/Akt pathway, FGF receptor activation signals primarily through the PKC pathway. ${ }^{60}$ However, both VEGF and basic fibroblast growth factor can initiate signal transduction through the extracellular signal-regulated kinase (ERK1) pathway. ${ }^{60,61}$ The precise role of FGF in tumor-associated angiogenesis remains to be elu- 
cidated; however, it could have important clinical implications given the finding that serum FGF is elevated in patients whose gliomas escape treatment with VEGF receptor inhibitor AZD2171. ${ }^{54}$

In addition to the potent effects of VEGF and FGF, a number of other pro-angiogenic molecules are under investigation. Interleukin- 8 , a chemokine released by microglia as part of the inflammatory process, acts via CXCR1 and CXCR2 G-protein coupled receptors on endothelial cells ${ }^{39}$ and is expressed in adult glioma at levels proportional to tumor grade. ${ }^{62}$ Interleukin-8 is also highly expressed in pseudopalisading cells in GBM, consistent with the hypothesis that hypoxia induces its expression. ${ }^{39}$ Recent work indicates that the tumor suppressor protein ING4 regulates interleukin- 8 mediated angiogenesis in glioma via the transcription factor NF $\kappa$ B. ${ }^{63}$

SDF-1 and its receptor CXCR4 are also found in glioma, with the highest levels of expression in areas of necrosis and the vascular endothelium, and the levels correlate tightly with those of HIF $1 \alpha{ }^{64}$ Studies indicate that hypoxia regulates CXCR4 levels both via $\mathrm{HIF} 1 \alpha$ in pseudopalisading tumor cells and also via VEGF-mediated signaling in endothelial cells. ${ }^{3}$ In addition, in vitro experiments have shown that SDF-1 has a significant effect on glioma cell migration and proliferation. ${ }^{65} \mathrm{In}$ addition to the local effect of SDF-1 at the tumor site, studies indicate that systemic SDF-1 may increase mobilization of marrow-derived endothelial progenitor cells that contribute to tumor formation as part of the process of vasculogenesis. ${ }^{13,66}$ The impact of SDF-1 on vasculogenesis combined with the finding that patient serum SDF-1 increases when their gliomas escape treatment with the VEGF receptor inhibitor AZD2171, whereas circulating marrow-derived progenitor cells increase when gliomas progress after AZD2171 interruption. ${ }^{54}$

Recent studies have also demonstrated that molecules involved in neuronal pattering during embryogenesis may serve analogous functions in vascular patterning during angiogenesis. ${ }^{3}$ The best studied of this group of proteins in the context of tumor angiogenesis is the semaphorins, which signal via neuropilins and plexins. Neuropilins are found on vascular endothelial cells and function as receptors for VEGF. Neuropilin binding elicits a pro-angiogenic response without the permeability changes elicited by classical VEGF to VEGF-R2 signaling. ${ }^{67,68}$ Blocking neuropilin-1 has also been shown to decrease tumor angiogenesis and growth. ${ }^{69}$ In addition to the semaphorin-neuropilin pathway, eph-ephrin signaling, which is involved in axonal guidance, appears to play a role in angiogenesis and tumor vessel formation. ${ }^{70,71}$ Preliminary data indicate that SLIT2 may have both pro- and anti-angiogenic roles, depending on the particular roundabout (Robo) receptor activated. ${ }^{72} \mathrm{Fi}-$ nally, the delta-like 4 ligand-notch signaling pathway also has parallels in neuronal and blood vessel development. The delta-like 4 ligand is a selective inhibitor of VEGF via its action on VEGF-R2 and its co-receptor neuropilin-1, ${ }^{73,74}$ although its exact role in brain tumor angiogenesis is not well understood. ${ }^{3}$

ECM proteins are another class of molecules differentially expressed in glioma vessels relative to those in the normal adult brain, and capable of stimulating angiogenesis. ${ }^{36,75}$ The ECM protein with the clearest role in angiogenesis in tenascin- $\mathrm{C}$, which is not expressed in the adult brain, but in glioma it is localized to sites of angiogenesis at the invading tumor border. ${ }^{76}$ Tenascin-C has also been shown to promote endothelial cell migration during angiogenesis in an autocrine manner. ${ }^{77} \mathrm{Te}-$ nascin also promotes VEGF expression and focal adhesion kinase phosphorylation, which are both important to ongoing angiogenesis. Consistent with its role in tumor biology, a phase II trial of anti-tenascin-C antibody in GBM patients showed an increase in median survival. ${ }^{78}$ Another example of an ECM protein involved in angiogenesis is fibronectin. The oncofetal form of fibronectin is typically only expressed during embryogenesis, but it is also seen in GBM, and it is restricted to the vasculature, suggesting a role in angiogenesis. ${ }^{75,79}$ Finally, recent work indicates that laminin-8 is expressed in vascular basement membrane of GBM, and functional blocking of laminin-8 in an animal model of GBM-reduced tumor microvessel density and increased survival. ${ }^{80}$ Thus, targeting of tumor-specific ECM molecules may present an independent target for future anti-angiogenic therapies.

\section{Anti-angiogenic factors}

In human glioma, the balance of pro-angiogenic factors detailed earlier in this report and anti-angiogenic factors settles in favor of angiogenesis. A number of anti-angiogenic factors have been described and play an important role in tumor angiogenesis. Perhaps the best understood endogenous anti-angiogenic protein is angiostatin. ${ }^{10}$ Angiostatin is derived from degradation of plasminogen by proteases such as cathepsin D and MMPs, resulting in a molecule comprised of kringle domains 1 through $4 .^{81,82}$ Studies in mice indicate that angiostatin inhibits glioma angiogenesis and growth ${ }^{83,84}$ through binding of $\alpha_{\mathrm{v}} \beta_{3}$ on proliferating endothelial cells, result in apoptosis. ${ }^{81,85} \mathrm{NG} 2$ chondroitin sulfate proteoglycan made by tumor-associated pericytes acts in a pro-angiogenic manner by sequestering angiostatin and decreasing its bioactivity. ${ }^{86}$ Although not yet demonstrated to be a native cleavage product of thrombospondin, kringle 5 domain has been shown to promote several anti-angiogenic processes via binding to glucoseregulated protein 78 , a heat shock protein family member found on the cell surface of endothelial cells. ${ }^{87}$ Expression of kringle 5 domain in mouse glioma has been shown to decrease tumor angiogenesis. ${ }^{88}$ 
The thrombospondins (TSPs) are another family of proteins that serves an anti-angiogenic function. ${ }^{10}$ TSP1 is made by platelets, endothelial cells, and smooth muscle cells in normal tissue. ${ }^{89}$ In vitro, TSP1 reduces endothelial cell proliferation and induces apoptosis. ${ }^{90}$ The primary mediator of TSP1-mediated signaling is via the type 1 repeat domain (TSR) on TSP1 and the CD36 LIMP11 Emp structural homology domain-1 (CLESH1) domain of the CD36 receptor found on the surface of microvessel endothelial cells. ${ }^{91}$ TSR peptides derived from TSP1 have been shown to decrease glioma angiogenesis and growth in murine tumor models. ${ }^{92}$ TSP2 has actions similar to TSP1, which are also mediated via TSRs. Mice deficient in TSP2 transplanted with glioma demonstrated increased microvessel density and tumor size, compatible with an anti-angiogenic role for TSP2 in glioma. ${ }^{93}$

In a mechanism similar to angiostatin, endostatin is an anti-angiogenic molecule formed by proteolytic cleavage of collagen-18 in glioblastoma basement membrane by elastase, cathepsin-L, and specific MMPs. ${ }^{94-96}$ Multiple anti-angiogenic mechanisms have been demonstrated with endostatin-mediated signaling, including binding to $\alpha_{5} \beta_{1}$ integrin, inhibition of VEGF-R2, inhibition of focal adhesion kinase-mediated endothelial cell migration, blockage of pro-angiogenic MMP-2, and decreased expression of the anti-apoptotic molecule Bcl2. ${ }^{95,97}$ Endostatin is expressed at higher levels in high grade gliomas, suggesting that its anti-angiogenic effects are countered by increasing pro-angiogenic mediators with higher grade transformation. ${ }^{98}$ Multiple animal studies confirm a functional role of endostatin in decreasing tumor angiogenesis and growth in vivo. ${ }^{99,100}$ Analogous to endostatin, proteolytic cleavage of collagen- 4 by MMPs produces tumstatin, which early evidence suggests may play a role in inhibiting angiogenesis by interaction with $\alpha \mathrm{v} \beta_{3}$ integrin and PI3K pathways. ${ }^{101,102}$

Brain angiogenesis inhibitor-1 (BAI1), also known as vasculostatin, is expressed in glia and neurons of normal brain but not in blood vessels. In contrast, BAI1 is markedly reduced in glioblastomas. ${ }^{38}$ As discussed earlier in the context of thrombospondin-mediated signaling, BAI1 also produces anti-angiogenic actions via its TSR domains, although in the case of BAI1, this occurs via interaction with the cell surface integrin $\alpha_{\mathrm{v}} \beta_{3}{ }^{103}$ Animal studies indicate that BAI1 has an anti-angiogenic effect on gliomas and that this effect is mediated by TSR domain interactions. ${ }^{104,105}$

In contrast to a number of ECM proteins discussed earlier in this review that promote angiogenesis, one ECM protein that has been shown to have an anti-angiogenic effect in glioma is secreted protein acidic and rich in cysteine (SPARC), also known as osteonectin or BM-40. SPARC is involved in a number of basic biologic functions, including migration, proliferation, and survival. ${ }^{106}$ Expression of SPARC in the nervous system is limited to the angiogenic microvasculature, as well as the locus coeruleus and retinal astrocytes, but is not normally expressed in the cerebral cortex..$^{107-110}$ However, SPARC expression is present in both tumor cells and endothelial cells in gliomas of all grades, as well as in endothelial cells and astrocytes in the adjacent tissue. ${ }^{111}$ Recent work indicates that SPARC suppresses tumor vascularity via suppression of VEGF expression and secretion, which is accomplished by limiting the availability of the growth factor. ${ }^{110}$ In contrast to its negative effect on angiogenesis, SPARC appears to have a promoting effect on tumor invasiveness. ${ }^{112,113} \mathrm{~A}$ better understanding of these pathways is necessary before proceeding with antiSPARC therapies.

\section{TARGETING ANGIOGENESIS AS A MEANS OF SENSITIZING GLIOMAS TO OTHER TREATMENT MODALITIES}

Preclinical studies have found that anti-angiogenic therapies often fail to have direct cytotoxic effects on glioma cells, but instead create windows of therapeutic opportunity for other treatments, a finding that has influenced the design of clinical trials involving anti-angiogenic agents in glioma treatment. For example, it has been shown that VEGF-R2 blockade creates a "normalization window," which is a brief period lasting 1 to 2 weeks in a murine model during the time when there is increased pericyte coverage of blood vessels via upregulation of Ang-1 and degradation of the pathologically thick tumor vessel basement membrane via MMP activation, all of which leads to greater tumor oxygenation and increased sensitivity to radiation. ${ }^{114}$

Similarly, anti-angiogenic therapy with VEGF receptor inhibitor sunitinib has been shown to increase intratumoral distribution of temozolomide, the DNA damaging agent that is the standard of care for newly diagnosed glioblastomas, due to normalization of tumor vessels. ${ }^{115}$ These findings are the basis of multiple clinical trials combining anti-angiogenic therapy with the VEGF neutralizing antibody bevacizumab and DNA damaging chemotherapy agents such as irinotecan. ${ }^{52,53}$

\section{MOLECULAR BIOLOGY OF GLIOMA INVASION}

Glioma invasion is challenging to study because most of the animal models fail to mimic the invasiveness of human glioma cells along white matter tracts. The best models available at present include: 1) Matrigel invasion chambers (BD Biosciences, Franklin Lakes, NJ) for in vitro studies; 2) xenograft lines that are serially passaged in vivo, which avoid the ability of prolonged passage in culture to inhibit invasiveness, a problem with cell lines; 


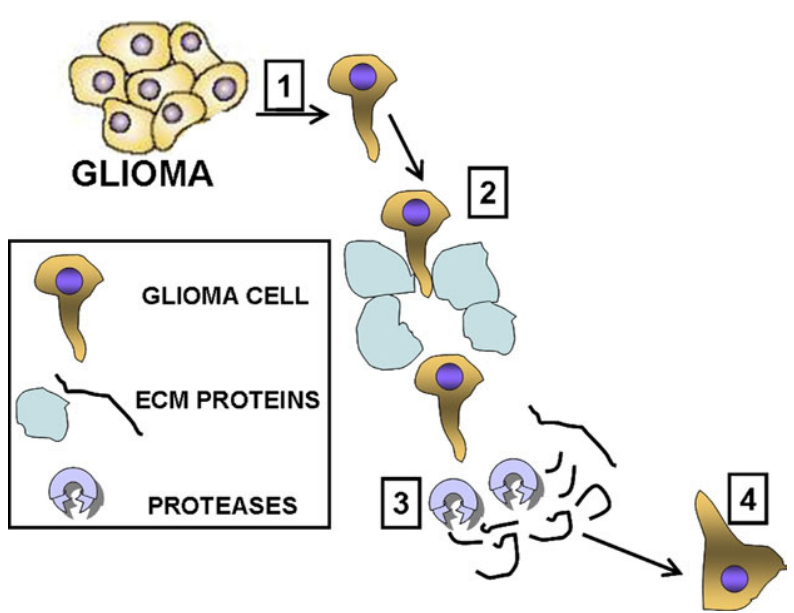

FIG. 3. Biology of glioma invasion. Glioma invasion involves 4 distinct processes: 1) glioma cell detachment from the primary mass involving neural cell adhesion molecule downregulation and CD44 cleavage; 2) mediators like integrin $\alpha_{v} \beta_{3}$ bind to the extracellular matrix (ECM); 3) glioma cells secrete proteases like MMPs, which degrade the ECM, under regulation of transcriptional factors like NF-кB; and 4) cytoplasmic mediators like myosin promote intracellular contractility, allowing glioma cells to alter their shape, such that a prominent leading cytoplasmic process is followed by a burst of forward movement by the cell body.

$1163)$ implanted glioma stem cells, which produce intracranial tumors with a greater degree of invasiveness than cell line-derived xenografts; ${ }^{2}$ and 4) transgenic mice lacking certain oncogenes that form spontaneous gliomas can exhibit a degree of invasiveness as well. ${ }^{117,118}$

Tumor cell invasion requires four distinct steps: 1) detachment of invading cells from the primary tumor mass; 2) adhesion to the ECM; 3) degradation of the ECM; and 4) cell motility and contractility (FIG. 3). Neural stem cell migration has been found to require these same steps, and many of the mediators of glioma invasion have been the same factors mediating neural stem cell migration.

The detachment of invading glioma cells from the primary tumor mass involves several events, including: 1) destabilization and disorganization of the cadherinmediated junctions that hold the primary mass together; 2) loss of expression of neural cell adhesion molecule, which promotes adhesion to the primary tumor mass through homophilic binding; and 3) cleavage of CD44, which anchors the primary mass to the ECM by the metalloproteinase ADAM.

The most common molecules allowing glioma cells to adhere to the ECM are integrins, particularly the integrin $\alpha_{\mathrm{V}} \beta_{3}$, which binds fibronectin in the ECM. Several glioma-expressed factors have been found that regulate glioma integrin expression. Glioma urokinase plaminogen activator (uPA) secretion has been shown to lead to upregulated glioma $\alpha_{\mathrm{V}} \beta_{3}$ expression. ${ }^{119}$ Glioma expression of focal adhesion kinase, a nonreceptor cytoplasmic tyrosine kinase, has been shown to increase phosphory- lation of human enhancer of filamentation 1, which in turn stimulates PDGF-mediated stimulation of glioma integrin adhesion to the ECM. ${ }^{120}$

The most common proteases degrading the ECM as part of glioma invasion are MMPs, most notably MMP-2 and MMP-9, the most expressed glioma invasion-mediating factor, whose regulation has been extensively studied. ${ }^{121}$ Transcription factor NF- $\kappa \mathrm{B}$ plays a role in both glioma cell adhesion to and degradation of ECM, by promoting transcription of UPA and MMP-9, and NF- $\kappa \mathrm{B}$ blockade has been shown to reduce glioma cell invasion in a matrigel assay. ${ }^{122}$ It has recently been shown that low-density lipoprotein receptor-related protein 1 , a multifunctional endocytic receptor involved in the metabolism of various extracellular ligands, promotes glioma invasion by inducing the expression of MMP-2 and MMP-9 through an ERK-dependent signaling pathway. ${ }^{123}$ Another group found that glioma cell interaction with normal brain tissue induced CD95 ligand expression in the brain tissue, which binds CD95 on glioma cells, recruiting Src family member Yes and the p85 subunit of PI3-kinase to CD95, leading to the expression of MMP-2 and MMP-9. ${ }^{124}$ Another MMP regulator is insulin-like growth factor binding protein-2, which, when transfected into glioma cells enhances their invasion through matrigel by upregulating MMP-2 expression. ${ }^{125}$ The insulin-like growth factor binding protein-2 is overexpressed by $40 \%$ to $50 \%$ of glioblastomas that exhibit loss of the tumor suppressor gene phosphatase and tensin homology deleted on chromosome $10 .{ }^{126}$ And another group found that gliomas express the receptor tyrosine kinase c-Met, which, when activated by its ligand scatter factor/hepatocyte growth factor in a paracrine or autocrine fashion, stimulates glioma secretion of uPA, which converts circulating plasminogen into plasmin, which activates several MMPs. ${ }^{127}$ Hypoxia has been shown to upregulate c-Met expression, which enhances scatter factor/hepatocyte growth factor-induced cell migration. ${ }^{128}$ In addition to MMPs, other studies have identified the protease cathepsin B as an important mediator of ECM degradation secreted by gliomas.

Glioma cells migrate like nontransformed neural progenitor cells - extending a prominent leading cytoplasmic process followed by a burst of forward movement by the cell body. As is the case with neural progenitor cells, the part of glioma motility and contractility involving this burst of forward movement by the cell body requires the $\mathrm{A}$ and $\mathrm{B}$ isoforms of myosin II. ${ }^{129}$ Myosin II allows glioma cells to squeeze through pores smaller than their nuclear diameter, which is important because the brain has particularly constrictive submicrometer extracellular spaces. ${ }^{129}$

Many mediators of glioma invasion such as c-Met or uPA are also capable of mildly stimulating angiogenesis. However, recent studies have shown that a murine gli- 
oma cell line derived from transgenic mice lacking VEGF expression forms tumors with irregular borders and increased invasiveness along blood vessels (perivascular invasion), as compared with the sharp borders seen in tumors derived from the same glioma cells transfected to overexpress VEGF. ${ }^{54,130}$ This observation may account for the finding that gliomas successfully treated with VEGF neutralizing antibody bevacizumab (avastin) often end up developing a nonenhancing infiltrating appearance on MRI suggestive of reduced vascularity and increased invasion, ${ }^{131}$ a potentially important mechanism of evasion to anti-angiogenic therapy in gliomas. ${ }^{132}$ Indeed, a preclinical study from 2003, years before bevacizumab treatment of gliomas underwent clinical trials, showed that anti-angiogenic therapy of murine gliomas with an antibody against VEGF-R2 caused small satellite tumors to arise near the primary mass, with these satellites centered around core vessels, akin to the perivascular invasion found more recently in the VEGF knockout glioma cell lines previously described. ${ }^{133}$ Further work will be needed to identify mediators of this invasion and to determine whether the invasion seen after bevacizumab treatment of human glioblastomas is the perivascular invasion seen in the murine cell lines or the parenchymal invasion along white matters that is typically seen with glioblastomas.

In terms of clinical trials targeting glioma invasion, the most notable to date was a randomized phase II study of Cilengitide (Merck KGaA, Darmastadt, Germany), an inhibitor of the integrins $\alpha_{\mathrm{V}} \beta_{3}$ and $\alpha_{\mathrm{V}} \beta_{5}$, which proved safe and was associated with a median survival of 10 months in recurrent glioma patients. ${ }^{134}$ Histologic sampling of the margins of treated tumors would be the ideal way of confirming an inhibitory effect on invasion in a clinical trial, but it is likely difficult to be accomplished in patients.

\section{CONCLUSIONS}

Glioblastoma remains a therapeutic challenge for clinicians given its highly aggressive nature and resistance to current therapies. Dysfunctional angiogenesis, a hallmark of glioblastoma, certainly contributes to the difficulty in treating this disease via breakdown of the BBB and subsequent alteration in transport of both physiologic and therapeutic molecules. Invasion along white matter tracts allows gliomas to extend at a microscopic level beyond surgical resection cavities or radiation treatment fields. Recent advances in the understanding of basic processes and molecular pathways underlying formation of abnormal blood vessels in glioma and their invasion, as discussed in this review, provide an exciting set of potential targets for therapeutic intervention. Future work further elucidating these basic angiogenic and invasion mechanisms and translating these discoveries to the clinical realm holds the promise of improving the lives of those patients affected by this unfortunate disease.

\section{REFERENCES}

1. Gilbertson RJ, Rich JN. Making a tumour's bed: glioblastoma stem cells and the vascular niche. Nat Rev Cancer 2007;7:733736 .

2. Singh SK, Hawkins C, Clarke ID, et al. Identification of human brain tumour initiating cells. Nature 2004;432:396-401.

3. Jain RK, di Tomaso E, Duda DG, Loeffler JS, Sorensen AG, Batchelor TT. Angiogenesis in brain tumours. Nat Rev Neurosci 2007;8:610-622.

4. Folkman J. Angiogenesis. Annu Rev Med 2006;57:1-18.

5. Plate KH, Mennel HD. Vascular morphology and angiogenesis in glial tumors. Exp Toxicol Pathol 1995;47:89-94.

6. Valk PE, Mathis CA, Prados MD, Gilbert JC, Budinger TF. Hypoxia in human gliomas: demonstration by PET with fluorine18-fluoromisonidazole. J Nucl Med 1992;33:2133-2137.

7. Kleihues P, Burger PC, Plate KH, Ohgaki H, Cavenee WK. Glioblastoma. In: Kleihues P, Cavenee WK, eds. Tumors of the Nervous System. Lyon: IARC Press; 2000. p. 16-26.

8. Hobbs SK, Monsky WL, Yuan F, et al. Regulation of transport pathways in tumor vessels: role of tumor type and microenvironment. Proc Natl Acad Sci U S A 1998;95:4607-4612.

9. Jain RK. Barriers to drug delivery in solid tumors. Sci Am 1994; 271:58-65.

10. Anderson JC, McFarland BC, Gladson CL. New molecular targets in angiogenic vessels of glioblastoma tumours. Expert Rev Mol Med 2008;10:e23.

11. Aghi M, Chiocca EA. Contribution of bone marrow-derived cells to blood vessels in ischemic tissues and tumors. Mol Ther 2005; 12:994-1005.

12. Jouanneau E. Angiogenesis and gliomas: current issues and development of surrogate markers. Neurosurgery 2008;62:31-50.

13. Aghi M, Cohen KS, Klein RJ, Scadden DT, Chiocca EA. Tumor stromal-derived factor-1 recruits vascular progenitors to mitotic neovasculature, where microenvironment influences their differentiated phenotypes. Cancer Res 2006;66:9054-9064.

14. Du R, Lu KV, Petritsch C, et al. HIF1alpha induces the recruitment of bone marrow-derived vascular modulatory cells to regulate tumor angiogenesis and invasion. Cancer Cell 2008;13: 206-220.

15. Bergers G, Song S. The role of pericytes in blood-vessel formation and maintenance. Neuro Oncol 2005;7:452-464.

16. Reiss Y, Machein MR, Plate KH. The role of angiopoietins during angiogenesis in gliomas. Brain Pathol 2005;15:311-317.

17. Zagzag D, Amirnovin R, Greco MA, et al. Vascular apoptosis and involution in gliomas precede neovascularization: a novel concept for glioma growth and angiogenesis. Lab Invest 2000;80: 837-849.

18. Stratmann A, Risau W, Plate KH. Cell type-specific expression of angiopoietin-1 and angiopoietin-2 suggests a role in glioblastoma angiogenesis. Am J Pathol 1998;153:1459-1466.

19. Holash J, Maisonpierre PC, Compton D, et al. Vessel cooption, regression, and growth in tumors mediated by angiopoietins and VEGF. Science 1999;284:1994-1998.

20. Hu B, Guo P, Fang Q, et al. Angiopoietin-2 induces human glioma invasion through the activation of matrix metalloprotease-2. Proc Natl Acad Sci U S A 2003;100:8904-8909.

21. Rooprai HK, McCormick D. Proteases and their inhibitors in human brain tumours: a review. Anticancer Res 1997;17:41514162.

22. Raithatha SA, Muzik H, Rewcastle NB, Johnston RN, Edwards DR, Forsyth PA. Localization of gelatinase-A and gelatinase-B mRNA and protein in human gliomas. Neuro Oncol 2000;2:145150.

23. Rao JS, Yamamoto M, Mohaman S, et al. Expression and localization of $92 \mathrm{kDa}$ type IV collagenase/gelatinase B (MMP-9) in human gliomas. Clin Exp Metastasis 1996;14:12-18. 
24. Guo P, Imanishi Y, Cackowski FC, et al. Up-regulation of angiopoietin-2, matrix metalloprotease-2, membrane type 1 metalloprotease, and laminin 5 gamma 2 correlates with the invasiveness of human glioma. Am J Pathol 2005;166:877-890.

25. Lakka SS, Gondi CS, Rao JS. Proteases and glioma angiogenesis. Brain Pathol 2005;15:327-341.

26. Kalluri R. Basement membranes: structure, assembly and role in tumour angiogenesis. Nat Rev Cancer 2003;3:422-433.

27. Oz B, Karayel FA, Gazio NL, Ozlen F, Balci K. The distribution of extracellular matrix proteins and CD44S expression in human astrocytomas. Pathol Oncol Res 2000;6:118-124.

28. Brooks PC, Clark RA, Cheresh DA. Requirement of vascular integrin alpha v beta 3 for angiogenesis. Science 1994;264:569571.

29. Gladson CL. Expression of integrin alpha v beta 3 in small blood vessels of glioblastoma tumors. J Neuropathol Exp Neurol 1996; 55:1143-1149.

30. Kim S, Bell K, Mousa SA, Varner JA. Regulation of angiogenesis in vivo by ligation of integrin alpha5betal with the central cell-binding domain of fibronectin. Am J Pathol 2000;156:1345-1362.

31. Ferrara N, Kerbel RS. Angiogenesis as a therapeutic target. Nature 2005;438:967-974.

32. Roberts WG, Whalen PM, Soderstrom E, et al. Antiangiogenic and antitumor activity of a selective PDGFR tyrosine kinase inhibitor, CP-673,451. Cancer Res 2005;65:957-966.

33. Herold-Mende C, Mueller MM, Bonsanto MM, Schmitt HP, Kunze S, Steiner HH. Clinical impact and functional aspects of tenascin- $\mathrm{C}$ expression during glioma progression. Int $\mathrm{J}$ Cancer 2002;98:362-369.

34. Baluk P, Morikawa S, Haskell A, Mancuso M, McDonald DM. Abnormalities of basement membrane on blood vessels and endothelial sprouts in tumors. Am J Pathol 2003;163:1801-1815.

35. Vitolo D, Paradiso P, Uccini S, Ruco LP, Baroni CD. Expression of adhesion molecules and extracellular matrix proteins in glioblastomas: relation to angiogenesis and spread. Histopathology 1996;28:521-528.

36. Wang D, Anderson JC, Gladson CL. The role of the extracellular matrix in angiogenesis in malignant glioma tumors. Brain Pathol 2005; 15:318-326.

37. Brown JM, Wilson WR. Exploiting tumour hypoxia in cancer treatment. Nat Rev Cancer 2004;4:437-447.

38. Kaur B, Brat DJ, Calkins CC, Van Meir EG. Brain angiogenesis inhibitor 1 is differentially expressed in normal brain and glioblastoma independently of p53 expression. Am J Pathol 2003; 162:19-27.

39. Brat DJ, Bellail AC, Van Meir EG. The role of interleukin-8 and its receptors in gliomagenesis and tumoral angiogenesis. Neuro Oncol 2005;7:122-133.

40. Desbaillets I, Diserens AC, de Tribolet N, Hamou MF, Van Meir EG. Regulation of interleukin-8 expression by reduced oxygen pressure in human glioblastoma. Oncogene 1999;18:1447-1456.

41. Fischer I, Gagner JP, Law M, Newcomb EW, Zagzag D. Angiogenesis in gliomas: biology and molecular pathophysiology. Brain Pathol 2005;15:297-310.

42. Kaur B, Tan C, Brat DJ, Post DE, Van Meir EG. Genetic and hypoxic regulation of angiogenesis in gliomas. J Neurooncol 2004;70:229-243.

43. Hanahan D, Folkman J. Patterns and emerging mechanisms of the angiogenic switch during tumorigenesis. Cell 1996;86:353-364.

44. Carmeliet P, Jain RK. Angiogenesis in cancer and other diseases. Nature 2000;407:249-257.

45. Dvorak HF. Vascular permeability factor/vascular endothelial growth factor: a critical cytokine in tumor angiogenesis and a potential target for diagnosis and therapy. J Clin Oncol 2002;20: $4368-4380$.

46. Ferrara N. Vascular endothelial growth factor: basic science and clinical progress. Endocr Rev 2004;25:581-611.

47. Machein MR, Plate KH. VEGF in brain tumors. J Neurooncol 2000;50:109-120.

48. Plate KH, Breier G, Weich HA, Risau W. Vascular endothelial growth factor is a potential tumour angiogenesis factor in human gliomas in vivo. Nature 1992;359:845-848.
49. Whitelock JM, Murdoch AD, Iozzo RV, Underwood PA. The degradation of human endothelial cell-derived perlecan and release of bound basic fibroblast growth factor by stromelysin, collagenase, plasmin, and heparanases. J Biol Chem 1996;271: 10079-10086.

50. Grau SJ, Trillsch F, Herms J, et al. Expression of VEGFR3 in glioma endothelium correlates with tumor grade. J Neurooncol 2007;82:141-150.

51. Jain RK. Molecular regulation of vessel maturation. Nat Med 2003;9:685-693.

52. Vredenburgh JJ, Desjardins A, Herndon JE, 2nd, et al. Phase II trial of bevacizumab and irinotecan in recurrent malignant glioma. Clin Cancer Res 2007;13:1253-1259.

53. Vredenburgh JJ, Desjardins A, Herndon JE, 2nd, et al. Bevacizumab plus irinotecan in recurrent glioblastoma multiforme. J Clin Oncol 2007;25:4722-4729.

54. Batchelor TT, Sorensen AG, di Tomaso E, et al. AZD2171, a pan-VEGF receptor tyrosine kinase inhibitor, normalizes tumor vasculature and alleviates edema in glioblastoma patients. Cancer Cell 2007;11:83-95.

55. Tabatabai G, Frank B, Wick A, et al. Synergistic antiglioma activity of radiotherapy and enzastaurin. Ann Neurol 2007;61: $153-161$.

56. Karcher S, Steiner HH, Ahmadi R, et al. Different angiogenic phenotypes in primary and secondary glioblastomas. Int J Cancer 2006;118:2182-2189.

57. Yamada SM, Yamada S, Hayashi Y, Takahashi H, Teramoto A, Matsumoto K. Fibroblast growth factor receptor (FGFR) 4 correlated with the malignancy of human astrocytomas. Neurol Res 2002;24:244-248.

58. Ueba T, Takahashi JA, Fukumoto M, et al. Expression of fibroblast growth factor receptor-1 in human glioma and meningioma tissues. Neurosurgery 1994;34:221-225.

59. Morrison RS, Yamaguchi F, Bruner JM, Tang M, McKeehan W, Berger MS. Fibroblast growth factor receptor gene expression and immunoreactivity are elevated in human glioblastoma multiforme. Cancer Res 1994;54:2794-2799.

60. Simons M. Integrative signaling in angiogenesis. Mol Cell Biochem 2004;264:99-102.

61. Pintucci G, Moscatelli D, Saponara F, et al. Lack of ERK activation and cell migration in FGF-2-deficient endothelial cells. FASEB J 2002;16:598-600.

62. Melder RJ, Koenig GC, Witwer BP, Safabakhsh N, Munn LL, Jain RK. During angiogenesis, vascular endothelial growth factor and basic fibroblast growth factor regulate natural killer cell adhesion to tumor endothelium. Nat Med 1996;2:992-997.

63. Garkavtsev I, Kozin SV, Chernova O, et al. The candidate tumour suppressor protein ING4 regulates brain tumour growth and angiogenesis. Nature 2004;428:328-332.

64. Zagzag D, Lukyanov Y, Lan L, et al. Hypoxia-inducible factor 1 and VEGF upregulate CXCR4 in glioblastoma: implications for angiogenesis and glioma cell invasion. Lab Invest 2006;86:12211232 .

65. Bajetto A, Barbieri F, Dorcaratto A, et al. Expression of CXC chemokine receptors 1-5 and their ligands in human glioma tissues: role of CXCR4 and SDF1 in glioma cell proliferation and migration. Neurochem Int 2006;49:423-432.

66. Hattori K, Heissig B, Tashiro K, et al. Plasma elevation of stromal cell-derived factor- 1 induces mobilization of mature and immature hematopoietic progenitor and stem cells. Blood 2001;97: 3354-3360.

67. Mamluk R, Klagsbrun M, Detmar M, Bielenberg DR. Soluble neuropilin targeted to the skin inhibits vascular permeability Angiogenesis 2005;8:217-227.

68. Soker S, Takashima S, Miao HQ, Neufeld G, Klagsbrun M Neuropilin-1 is expressed by endothelial and tumor cells as an isoform-specific receptor for vascular endothelial growth factor. Cell 1998;92:735-745.

69. Miao HQ, Klagsbrun M. Neuropilin is a mediator of angiogenesis. Cancer Metastasis Rev 2000;19:29-37.

70. Kuijper S, Turner CJ, Adams RH. Regulation of angiogenesis by Eph-ephrin interactions. Trends Cardiovasc Med 2007;17:145151. 
71. Yancopoulos GD, Davis S, Gale NW, Rudge JS, Wiegand SJ, Holash J. Vascular-specific growth factors and blood vessel formation. Nature 2000;407:242-248.

72. Cirulli V, Yebra M. Netrins: beyond the brain. Nat Rev Mol Cell Biol 2007;8:296-306.

73. Leslie JD, Ariza-McNaughton L, Bermange AL, McAdow R, Johnson SL, Lewis J. Endothelial signalling by the Notch ligand Delta-like 4 restricts angiogenesis. Development 2007;134:839844.

74. Williams CK, Li JL, Murga M, Harris AL, Tosato G. Up-regulation of the Notch ligand Delta-like 4 inhibits VEGF-induced endothelial cell function. Blood 2006;107:931-939.

75. Castellani P, Viale G, Dorcaratto A, et al. The fibronectin isoform containing the ED-B oncofetal domain: a marker of angiogenesis. Int J Cancer 1994;59:612-618.

76. Zagzag D, Friedlander DR, Dosik J, et al. Tenascin-C expression by angiogenic vessels in human astrocytomas and by human brain endothelial cells in vitro. Cancer Res 1996;56:182-189.

77. Zagzag D, Shiff B, Jallo GI, et al. Tenascin-C promotes microvascular cell migration and phosphorylation of focal adhesion kinase. Cancer Res 2002;62:2660-2668.

78. Akabani G, Reardon DA, Coleman RE, et al. Dosimetry and radiographic analysis of 131I-labeled anti-tenascin 81C6 murine monoclonal antibody in newly diagnosed patients with malignant gliomas: a phase II study. J Nucl Med 2005;46:1042-1051.

79. Mariani G, Lasku A, Balza E, et al. Tumor targeting potential of the monoclonal antibody BC-1 against oncofetal fibronectin in nude mice bearing human tumor implants. Cancer 1997;80:2378 2384.

80. Fujita M, Khazenzon NM, Ljubimov AV, et al. Inhibition of laminin-8 in vivo using a novel poly(malic acid)-based carrier reduces glioma angiogenesis. Angiogenesis 2006;9:183-191.

81. Wahl ML, Kenan DJ, Gonzalez-Gronow M, Pizzo SV. Angiostatin's molecular mechanism: aspects of specificity and regulation elucidated. J Cell Biochem 2005;96:242-261.

82. O’Reilly MS, Holmgren L, Shing Y, et al. Angiostatin: a novel angiogenesis inhibitor that mediates the suppression of metastases by a Lewis lung carcinoma. Cell 1994;79:315-328.

83. Kirsch M, Strasser J, Allende R, Bello L, Zhang J, Black PM. Angiostatin suppresses malignant glioma growth in vivo. Cancer Res 1998;58:4654-4659.

84. Joe YA, Hong YK, Chung DS, et al. Inhibition of human malignant glioma growth in vivo by human recombinant plasminogen kringles 1-3. Int J Cancer 1999;82:694-699.

85. Tarui T, Miles LA, Takada Y. Specific interaction of angiostatin with integrin alpha(v)beta(3) in endothelial cells. J Biol Chem 2001;276:39562-39568.

86. Chekenya M, Hjelstuen M, Enger PO, et al. NG2 proteoglycan promotes angiogenesis-dependent tumor growth in CNS by sequestering angiostatin. FASEB J 2002;16:586-588.

87. Davidson DJ, Haskell C, Majest S, et al. Kringle 5 of human plasminogen induces apoptosis of endothelial and tumor cells through surface-expressed glucose-regulated protein 78 . Cancer Res 2005;65:4663-4672.

88. Perri SR, Nalbantoglu J, Annabi B, et al. Plasminogen kringle 5-engineered glioma cells block migration of tumor-associated macrophages and suppress tumor vascularization and progression. Cancer Res 2005;65:8359-8365.

89. Adams JC, Lawler J. The thrombospondins. Int J Biochem Cell Biol 2004;36:961-968.

90. Nor JE, Mitra RS, Sutorik MM, Mooney DJ, Castle VP, Polverini PJ. Thrombospondin-1 induces endothelial cell apoptosis and inhibits angiogenesis by activating the caspase death pathway. $\mathrm{J}$ Vasc Res 2000;37:209-218.

91. Simantov R, Silverstein RL. CD36: a critical anti-angiogenic receptor. Front Biosci 2003;8:s874-s882.

92. Anderson JC, Grammer JR, Wang W, et al. ABT-510, a modified type 1 repeat peptide of thrombospondin, inhibits malignant glioma growth in vivo by inhibiting angiogenesis. Cancer Biol Ther 2007;6:454-462.

93. Fears CY, Grammer JR, Stewart JE, Jr., et al. Low-density lipoprotein receptor-related protein contributes to the antiangio- genic activity of thrombospondin-2 in a murine glioma model. Cancer Res 2005;65:9338-9346.

94. Strik HM, Weller M, Frank B, et al. Heat shock protein expression in human gliomas. Anticancer Res 2000;20:4457-4462.

95. Folkman J. Antiangiogenesis in cancer therapy-endostatin and its mechanisms of action. Exp Cell Res 2006;312:594-607.

96. Heljasvaara R, Nyberg P, Luostarinen J, et al. Generation of biologically active endostatin fragments from human collagen XVIII by distinct matrix metalloproteases. Exp Cell Res 2005; 307:292-304.

97. Sudhakar A, Sugimoto H, Yang C, Lively J, Zeisberg M, Kalluri R. Human tumstatin and human endostatin exhibit distinct antiangiogenic activities mediated by alpha v beta 3 and alpha 5 beta 1 integrins. Proc Natl Acad Sci U S A 2003;100:4766-4771.

98. Morimoto T, Aoyagi M, Tamaki M, et al. Increased levels of tissue endostatin in human malignant gliomas. Clin Cancer Res 2002;8:2933-2938.

99. Barnett FH, Scharer-Schuksz M, Wood M, Yu X, Wagner TE, Friedlander M. Intra-arterial delivery of endostatin gene to brain tumors prolongs survival and alters tumor vessel ultrastructure. Gene Ther 2004;11:1283-1289.

100. Sorensen DR, Read TA, Porwol T, et al. Endostatin reduces vascularization, blood flow, and growth in a rat gliosarcoma. Neuro Oncol 2002;4:1-8.

101. Maeshima Y, Colorado PC, Kalluri R. Two RGD-independent alpha vbeta 3 integrin binding sites on tumstatin regulate distinct anti-tumor properties. J Biol Chem 2000;275:23745-23750.

102. Mundel TM, Kalluri R. Type IV collagen-derived angiogenesis inhibitors. Microvasc Res 2007;74:85-89.

103. Koh JT, Kook H, Kee HJ, et al. Extracellular fragment of brainspecific angiogenesis inhibitor 1 suppresses endothelial cell proliferation by blocking alphavbeta5 integrin. Exp Cell Res 2004; 294:172-184.

104. Kang X, Xiao X, Harata M, et al. Antiangiogenic activity of BAI1 in vivo: implications for gene therapy of human glioblastomas. Cancer Gene Ther 2006;13:385-392.

105. Kaur B, Brat DJ, Devi NS, Van Meir EG. Vasculostatin, a proteolytic fragment of brain angiogenesis inhibitor 1 , is an antiangiogenic and antitumorigenic factor. Oncogene 2005;24:36323642 .

106. Bornstein P, Sage EH. Matricellular proteins: extracellular modulators of cell function. Curr Opin Cell Biol 2002;14:608-616.

107. Lane TF, Iruela-Arispe ML, Johnson RS, Sage EH. SPARC is a source of copper-binding peptides that stimulate angiogenesis. J Cell Biol 1994;125:929-943.

108. Yan Q, Sage EH, Hendrickson AE. SPARC is expressed by ganglion cells and astrocytes in bovine retina. J Histochem $\mathrm{Cy}$ tochem 1998;46:3-10.

109. Lane TF, Sage EH. The biology of SPARC, a protein that modulates cell-matrix interactions. FASEB J 1994;8:163-173.

110. Yunker CK, Golembieski W, Lemke N, et al. SPARC-induced increase in glioma matrix and decrease in vascularity are associated with reduced VEGF expression and secretion. Int J Cancer 2008;122:2735-2743.

111. Rempel SA, Golembieski WA, Ge S, et al. SPARC: a signal of astrocytic neoplastic transformation and reactive response in human primary and xenograft gliomas. J Neuropathol Exp Neurol 1998;57:1112-1121.

112. Golembieski WA, Ge S, Nelson K, Mikkelsen T, Rempel SA. Increased SPARC expression promotes U87 glioblastoma invasion in vitro. Int J Dev Neurosci 1999;17:463-472.

113. Schultz C, Lemke N, Ge S, Golembieski WA, Rempel SA. Secreted protein acidic and rich in cysteine promotes glioma invasion and delays tumor growth in vivo. Cancer Res 2002;62:62706277.

114. Winkler F, Kozin SV, Tong RT, et al. Kinetics of vascular normalization by VEGFR2 blockade governs brain tumor response to radiation: role of oxygenation, angiopoietin- 1 , and matrix metalloproteinases. Cancer Cell 2004;6:553-563.

115. Zhou Q, Guo P, Gallo JM. Impact of angiogenesis inhibition by sunitinib on tumor distribution of temozolomide. Clin Cancer Res 2008;14:1540-1549. 
116. Giannini C, Sarkaria JN, Saito A, et al. Patient tumor EGFR and PDGFRA gene amplifications retained in an invasive intracranial xenograft model of glioblastoma multiforme. Neuro-oncol 2005; $7: 164-176$.

117. Alcantara Llaguno S, Chen J, Kwon CH, et al. Malignant astrocytomas originate from neural stem/progenitor cells in a somatic tumor suppressor mouse model. Cancer Cell 2009;15:45-56.

118. Zheng H, Ying H, Yan H, et al. p53 and Pten control neural and glioma stem/progenitor cell renewal and differentiation. Nature 2008;455:1129-1133.

119. Adachi Y, Lakka SS, Chandrasekar N, et al. Down-regulation of integrin alpha(v)beta(3) expression and integrin-mediated signaling in glioma cells by adenovirus-mediated transfer of antisense urokinase-type plasminogen activator receptor (uPAR) and sense p16 genes. J Biol Chem 2001;276:47171-47177.

120. Natarajan M, Stewart JE, Golemis EA, et al. HEF1 is a necessary and specific downstream effector of FAK that promotes the migration of glioblastoma cells. Oncogene 2006;25:1721-1732.

121. Rao JS. Molecular mechanisms of glioma invasiveness: the role of proteases. Nat Rev Cancer 2003;3:489-501.

122. Li L, Gondi CS, Dinh DH, Olivero WC, Gujrati M, Rao JS. Transfection with anti-p65 intrabody suppresses invasion and angiogenesis in glioma cells by blocking nuclear factor-kappaB transcriptional activity. Clin Cancer Res 2007;13:2178-2190.

123. Song H, Li Y, Lee J, Schwartz AL, Bu G. Low-density lipoprotein receptor-related protein 1 promotes cancer cell migration and invasion by inducing the expression of matrix metalloproteinases 2 and 9. Cancer Res 2009;69:879-886.

124. Kleber S, Sancho-Martinez I, Wiestler B, et al. Yes and PI3K bind CD95 to signal invasion of glioblastoma. Cancer Cell 2008; 13:235-248.

125. Wang $\mathrm{H}$, Shen $\mathrm{W}$, Huang $\mathrm{H}$, et al. Insulin-like growth factor binding protein 2 enhances glioblastoma invasion by activating invasion-enhancing genes. Cancer Res 2003;63:4315-4321.
126. Levitt RJ, Georgescu MM, Pollak M. PTEN-induction in U251 glioma cells decreases the expression of insulin-like growth factor binding protein-2. Biochem Biophys Res Commun 2005;336: $1056-1061$

127. Martens T, Schmidt NO, Eckerich C, et al. A novel one-armed anti-c-Met antibody inhibits glioblastoma growth in vivo. Clin Cancer Res 2006;12:6144-6152.

128. Eckerich C, Zapf S, Fillbrandt R, Loges S, Westphal M, Lamszus $\mathrm{K}$. Hypoxia can induce c-Met expression in glioma cells and enhance SF/HGF-induced cell migration. Int J Cancer 2007;121: 276-283.

129. Beadle C, Assanah MC, Monzo P, Vallee R, Rosenfeld SS, Canoll P. The role of myosin II in glioma invasion of the brain. Mol Biol Cell 2008;19:3357-3368.

130. Paez-Ribes M, Allen E, Hudock J, et al. Antiangiogenic therapy elicits malignant progression of tumors to increased local invasion and distant metastasis. Cancer Cell 2009;15:220-231.

131. Norden AD, Young GS, Setayesh K, et al. Bevacizumab for recurrent malignant gliomas: efficacy, toxicity, and patterns of recurrence. Neurology 2008;70:779-787.

132. Chi A, Norden AD, Wen PY. Inhibition of angiogenesis and invasion in malignant gliomas. Expert Rev Anticancer Ther 2007; 7:1537-1560.

133. Lamszus $\mathrm{K}$, Kunkel $\mathrm{P}$, Westphal M. Invasion as limitation to anti-angiogenic glioma therapy. Acta Neurochir Suppl 2003;88: 169-177.

134. Reardon DA, Fink KL, Mikkelsen T, et al. Randomized phase II study of cilengitide, an integrin-targeting arginine-glycine-aspartic acid peptide, in recurrent glioblastoma multiforme. J Clin Oncol 2008;26:5610-5617.

135. Rafii S, Lyden D, Benezra R, Hattori K, Heissig B. Vascular and haematopoietic stem cells: novel targets for anti-angiogenesis therapy? Nat Rev Cancer 2002;2:826-835. 